\title{
Distribution of Rose Black Spot (Diplocarpon rosae) Genetic Diversity in Eastern North America Using Amplified Fragment Length Polymorphism and Implications for Resistance Screening
}

\author{
Vance M. Whitaker and Stan C. Hokanson ${ }^{1}$ \\ Department of Horticultural Science, University of Minnesota, 258 Alderman Hall, 1970 Folwell \\ Avenue, St. Paul, MN 55108 \\ James Bradeen \\ Department of Plant Pathology, University of Minnesota, 495 Borlaug Hall, 1991 Upper Buford \\ Circle, St. Paul, MN 55108

\begin{abstract}
AdDitional INDEX wORDs. AMOVA, dendrogram, fungal isolate, Jaccard's coefficient, pathogenic race, principal component analysis

Abstract. Black spot, incited by the fungus Diplocarpon rosae Wolf, is the most significant disease problem of landscape roses (Rosa hybrida $\mathrm{L}$.) worldwide. The documented presence of pathogenic races necessitates that rose breeders screen germplasm with isolates that represent the range of $D$. rosae diversity for their target region. The objectives of this study were to characterize the genetic diversity of single-spore isolates from eastern North America and to examine their distribution according to geographic origin, host of origin, and race. Fifty isolates of $D$. rosae were collected from roses representing multiple horticultural classes in disparate locations across eastern North America and analyzed by amplified fragment length polymorphism. Considerable marker diversity among isolates was discovered, although phenetic and cladistic analyses revealed no significant clustering according to host of origin or race. Some clustering within collection locations suggested short-distance dispersal through asexual conidia. Lack of clustering resulting from geographic origin was consistent with movement of $D$. rosae on vegetatively propagated roses. Results suggest that field screening for black spot resistance in multiple locations may not be necessary; however, controlled inoculations with single-spore isolates representing known races is desirable as a result of the inherent limitations of field screening.
\end{abstract}

The fungus Diplocarpon rosae (anamorph = Marssonina rosae Lind.) is the causal organism of rose black spot, which is the most damaging disease of rose worldwide (Dobbs, 1984). Symptoms include lesions on leaves and stems as well as frequent leaf yellowing and defoliation that significantly compromise plant growth and appearance. Consequently, numerous topical and systemic fungicides are used by homeowners and landscapers to combat this disease. Diplocarpon rosae is classified as an ascomycete in the family Dermateaceae and is a hemibiotrophic fungus that is restricted to the genus Rosa L. (Blechert and Debener, 2005). It is spread primarily through waterborne, two-celled asexual spores (conidia) that require free water to germinate. Visual symptoms may develop in susceptible cultivars in as little as $4 \mathrm{~d}$ after spore germination and penetration. The sexual stage of this fungus has been reported only twice in North America and twice in England

Received for publication 27 Nov. 2006. Accepted for publication 30 Mar. 2007 This manuscript is Scientific Journal Series No. 061210167 of the University of Minnesota Department of Horticultural Science and has been supported in part by the Minnesota Agricultural Experiment Station.

We thank Dr. Campbell Davidson, Dennis Eveleigh, Sam Kedem, Helen Nowell, Nick Howell, Ann Creamer, Donna Fuss, Paul Zimmerman, Jim Jacobi, Kathy Kilgore, Glenn Schroeter, Diane Brueckman, Julie Overom, Kathy Ahlgren, and Charles Tubesing for collecting D. rosae isolates. We also acknowledge Marilena Aquino De Muro for contributing expertise in DNA extraction methodology.

${ }^{1}$ Corresponding author. E-mail: hokan017@umn.edu.
(Horst, 1983), although frequency of sexual recombination in D. rosae populations has not been determined.

Phenotypic variability among single-conidial isolates suggests that $D$. rosae is a genetically diverse pathogen (Wenefrida and Spencer, 1993). Pathogenicity tests have revealed the presence of numerous races. Five races were discovered in Germany (Debener et al., 1998) among 15 isolates, four have been found in England (Yokoya et al., 2000), four were described in Ontario, Canada (Svejda and Bolton, 1980), and seven races were described in Mississippi (Spencer and Wood, 1992a, 1992b). Although it is not known whether any of these races from different studies are the same, the occurrence of multiple races in each location suggests a large total number of races in the world. The Mississippi isolates were collected from a seven-county area demonstrating diversity in pathogenicity within a relatively narrow geographic range. Considerable variability in conidial size and colony color among singleconidial isolates has also been documented (Wenefrida and Spencer, 1993).

Genetic diversity has been documented in D. rosae using molecular marker analyses. Lee et al. (2000) examined 10 isolates using restriction fragment length polymorphism (RFLP) analysis of the internal transcribed spacer region of rDNA. Distinct RFLP patterns were observed and isolates clustered into three groups. Initial studies by British researchers with simple sequence repeat and amplified fragment length polymorphism (AFLP) indicated that AFLP was the more 
reproducible and sensitive marker system for their isolates, although final results of their work have not yet been published (Drewes-Alvarez, 2003). Carlson-Nilsson (2002) conducted a randomly amplified polymorphic DNA analysis of $15 \mathrm{D}$. rosae isolates collected from locations in Sweden, Canada, France, and the United States, which were roughly separated by geographic origin in a cluster analysis. The survey did not allow in-depth analysis of geography, host of origin, pathogenic race, fungicide selection, or other factors on genetic similarity among isolates, although diversity among isolates was demonstrated. The current lack of knowledge about such factors and their influence on diversity complicates host resistance breeding efforts.

The objective of this study was a preliminary examination of the genetic diversity present in 50 single-spore isolates of D. rosae collected from eastern North American using AFLP analysis (Vos et al., 1995) and the manner in which diversity was distributed in relation to geographic origin, host of origin, or pathogenic race structure of the isolates under study. Such information is useful for the screening and evaluation of host resistance in rose germplasm targeted for North American markets.

\section{Materials and Methods}

Collection. Leaves infected with D. rosae were collected from roses growing in 17 disparate locations across eastern North America (Table 1; Fig. 1). Collection sites were chosen to represent a broad range of locations across the eastern United States and southern Canada. Collection sites contained multiple rose plants in small nurseries or botanical/display gardens; therefore, distances between individual plants in collection sites ranged from less than $3 \mathrm{~m}$ to no more than a few hundred meters apart. The only exception were isolates MSD and MSBD, which were collected from the same residential garden in Duluth, MN, and isolate FCD, which was collected from a separate residential garden in the same city. A subset of leaf samples was purposefully collected from the same host cultivars in different geographical locations to examine possible effects of host of origin on the genetic diversity of $D$. rosae isolates. Infected leaves were stored at a temperature of $-20{ }^{\circ} \mathrm{C}$ for up to 4 months before pathogen isolation.

ISOLATION AND CULTURE. Fifty single-conidial isolates were isolated from infected leaf pieces and increased from single conidia (asexual spores) on potato dextrose agar (PDA) according to the methods described by Whitaker et al. (2007a). After $28 \mathrm{~d}$ of growth on PDA at room temperature, digital pictures were taken to record the colony color of all isolates. Conidia from each single-conidial isolate were harvested in a laminar flow hood by flooding petri plates with $\approx 5 \mathrm{~mL}$ sterile $\mathrm{ddH}_{2} \mathrm{O}$ and rubbing colonies with a sterile glass rod to dislodge conidia. Plates yielded between $10^{6}$ and $10^{7}$ conidia $/ \mathrm{mL}$. Conidia were concentrated by centrifuging at high speed for $3 \mathrm{~min}$ in 1.5-mL microfuge tubes and pouring off excess water. Tubes were frozen at $-20{ }^{\circ} \mathrm{C}$ until DNA was extracted.

In a separate study, 14 of the 50 isolates were selected for a race-test inoculation as described by Whitaker et al. (2007b). Briefly, these isolates were chosen by selecting one isolate at random from each of 14 separate locations. Twelve rose genotypes were selected for the race test to represent a range of genetic diversity and horticultural classes, including hybrid tea, hybrid gallica, miniflora, species, and shrub. Using these
Table 1. Fifty single-conidial isolates of Diplocarpon rosae, their geographic locations, and their host cultivars of origin. ${ }^{\mathrm{z}}$

\begin{tabular}{|c|c|c|c|}
\hline Isolate & Location & Host cultivar & $\operatorname{Rac}$ \\
\hline $\mathrm{CBB}$ & Birmingham, AL & Cecile Brunner & \\
\hline PEB & Birmingham, AL & Peace & A \\
\hline LPB & Birmingham, AL & Love and Peace & \\
\hline $\mathrm{NDCH}$ & Jemison, AL & New Dawn & 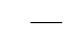 \\
\hline $\mathrm{CBCH}$ & Jemison, AL & Cecile Brunner & \\
\hline $\mathrm{HECH}$ & Jemison, AL & Heritage & \\
\hline $\mathrm{DDCH}$ & Jemison, AL & Dortmund & A \\
\hline $\mathrm{BACH}$ & Jemison, AL & Ballerina & 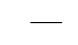 \\
\hline $\mathrm{SNC}$ & Bloomfield, CT & Starry Night & A \\
\hline PPC & Bloomfield, CT & Pink Panther & \\
\hline IGI & Ames, IA & Iceberg & - \\
\hline LPI & Ames, IA & Love and Peace & A \\
\hline CMI & Ames, IA & Charles de Mills & - \\
\hline GMI & Ames, IA & Gold Medal & \\
\hline PEL & Shreveport, LA & Peace & A \\
\hline UNM & Morden, MB & Unknown & A \\
\hline MSD & Duluth, MN & Morden Sunrise & - \\
\hline FCD & Duluth, MN & Frontenac & \\
\hline MSBD & Duluth, MN & Morden Snowbeauty & - \\
\hline BAH & Hastings, MN & Ballerina & - \\
\hline $\mathrm{HEH}$ & Hastings, MN & Heritage & \\
\hline LPH & Hastings, MN & Love and Peace & \\
\hline $\mathrm{JCH}$ & Hastings, MN & John Cabot & \\
\hline $\mathrm{GVH}$ & Hastings, MN & George Vancouver & $\mathrm{C}$ \\
\hline WBN & Chanhassen, $\mathrm{MN}$ & William Baffin & - \\
\hline BAN & Chanhassen, MN & Ballerina & - \\
\hline $\mathrm{JCN}$ & Chanhassen, MN & John Cabot & A \\
\hline $\mathrm{CMN}$ & Chanhassen, $\mathrm{MN}$ & Charles de Mills & - \\
\hline NWR & Rochester, MN & Nearly Wild & - \\
\hline LPM & St. Louis, MO & Love and Peace & - \\
\hline ANM & St. Louis, MO & Apricot Nectar & - \\
\hline BAM & St. Louis, MO & Ballerina & - \\
\hline HEM & St. Louis, MO & Heritage & - \\
\hline IGM & St. Louis, MO & Iceberg & - \\
\hline LEM & St. Louis, MO & Love's Promise & - \\
\hline DDM & St. Louis, MO & Dortmund & A \\
\hline IGO & Burlington, ON & Iceberg & - \\
\hline HEO & Burlington, ON & Heritage & - \\
\hline $\mathrm{MBO}$ & Burlington, ON & Morden Blush & A \\
\hline CBOD & Newark, OH & Cecile Brunner & A \\
\hline $\mathrm{COH}$ & Kirtland, $\mathrm{OH}$ & Carmenatta & - \\
\hline LFSC & Landrum, SC & La France & - \\
\hline CBSC & Landrum, SC & Cecile Brunner & - \\
\hline ANSC & Landrum, SC & Apricot Nectar & A \\
\hline IGSC & Landrum, SC & Iceberg & - \\
\hline BASC & Landrum, SC & Ballerina & - \\
\hline CMSC & Landrum, SC & Charles de Mills & - \\
\hline CET & Brenham, TX & Crepuscle & - \\
\hline $\mathrm{ACT}$ & Brenham, TX & Archduke Charles & A \\
\hline IGWA & Appleton, WI & Iceberg & B \\
\hline
\end{tabular}

${ }^{\mathrm{z}}$ Race characterizations of 14 randomly selected isolates are based on inoculation to a panel of 12 rose genotypes (Whitaker et al., 2007b).

${ }^{\mathrm{y}}$ Race not characterized.

host genotypes, three races (A, B, and C) were differentiated among the 14 isolates (Table 1). All isolates have been deposited in the University of Minnesota Mycological Culture Collection and are available for research use. 


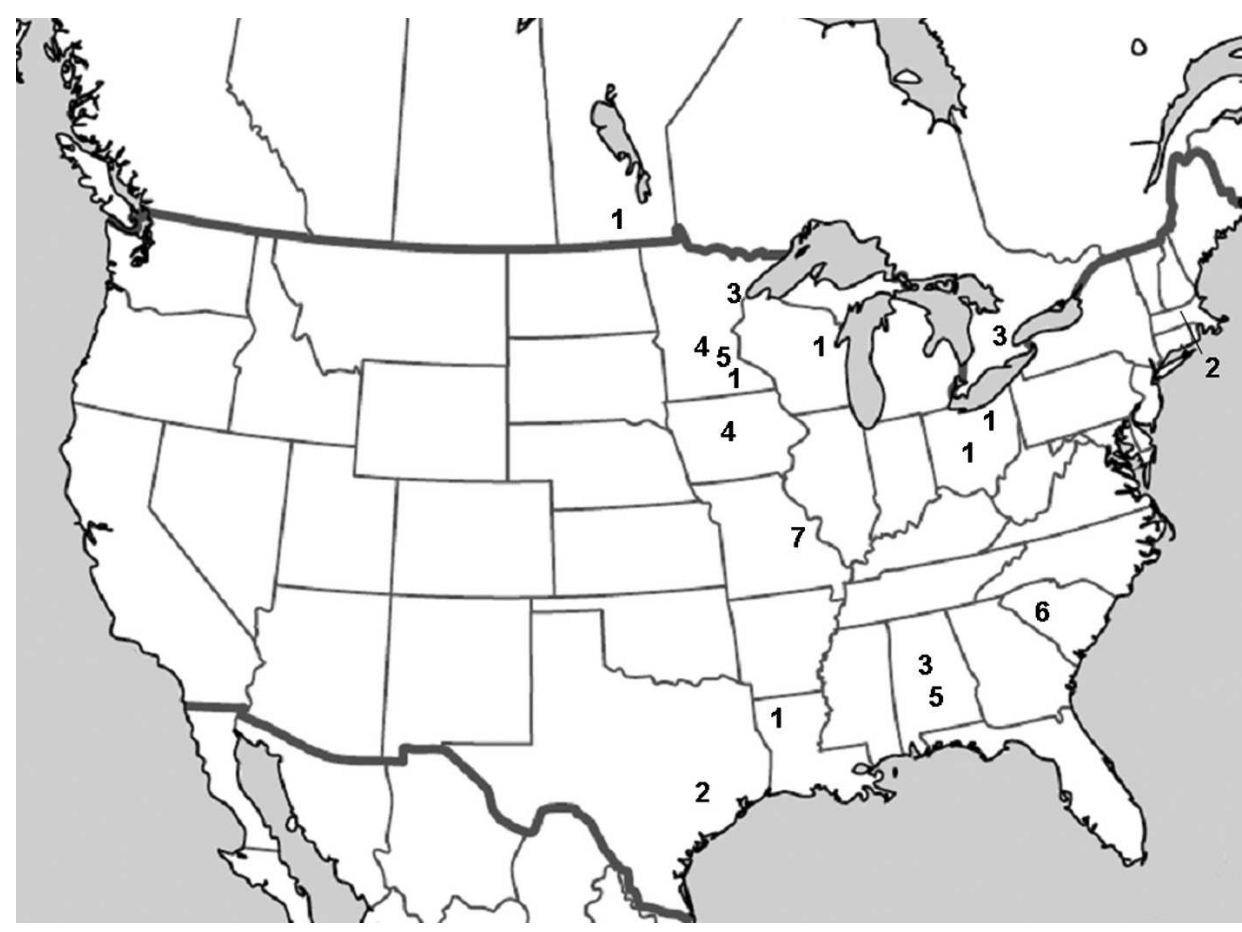

Fig. 1. Numbers of Diplocarpon rosae isolates collected from various rose cultivars growing in 17 locations across eastern North America.

DNA EXTRACTion. DNA was extracted using the OmniPrep DNA extraction kit (Geno Technology, St. Louis) with some protocol modifications. Conidia (30 to $50 \mathrm{mg}$ ) were incubated with 400 units crude lyticase from Arthrobacter luteus Conn. (Sigma Aldrich, St. Louis) in $300 \mu \mathrm{L}$ lysis buffer for $2 \mathrm{~h}$ at $33{ }^{\circ} \mathrm{C}$. The mixture was vortexed two to three times during incubation to promote cell wall degradation. Conidia were subsequently ground for 45 to $60 \mathrm{~s}$ with 30 to $40 \mu \mathrm{L}$ Molecular Grinding Resin (Geno Technology) using a handheld drill and sterile plastic pestle. An additional $300 \mu \mathrm{L}$ lysis buffer was added to the sample along with $10 \mu \mathrm{L}$ Long-Life Protease K (Geno Technology). Tubes were inverted several times to mix and then incubated for $2 \mathrm{~h}$ at $60^{\circ} \mathrm{C}$. The samples were vortexed two to three times during incubation. Samples were cooled to room temperature, and the manufacturer's protocol was completed according to kit instructions. The DNA pellet was resuspended in $50 \mu \mathrm{L}$ purified water and $1 \mu \mathrm{L}$ RNAse A (Geno Technology) before storing at $-20{ }^{\circ} \mathrm{C}$. DNA concentrations ranged from 20 to $50 \mathrm{ng} \cdot \mathrm{\mu L}^{-1}$ as determined with a DyNA Quant 200 Fluorometer (Hoefer, San Francisco). Electrophoresis on agarose gels confirmed the presence of large, undegraded DNA fragments greater than 10,000 base pairs (bp) (data not shown).

AMPlified FRAGMENT LENGTH POLYMORPHiSM ANALYSIS. AFLP analysis was performed using the Invitrogen AFLP Analysis System I kit (Invitrogen, Carlsbad, CA) according to the manufacturer's instructions with some modifications. Reaction volumes were reduced to one-fourth the recommended volume, and 20 to $50 \mathrm{ng}$ template DNA was added to a digestion with EcoRI (E) and MseI (M). The E primer for selective amplifications was end-labeled with ${ }^{33} \mathrm{P}$. Because the genome size of $D$. rosae has not been estimated and no previous AFLP analyses have been performed on this species, four different primer pairs (E-ACC/M-CT, E-AC/M-CTC, E-AC/M-CT, and
E-A/M-CT) were initially compared for isolates ANM, BAM, MSD, and SNC to examine the effect of primer length on band number. Selective amplifications for all 50 isolates were subsequently performed with four different E-A/M-CN primer pairs (Integrated DNA Technologies, Coralville, IA) (Table 2). The E-A primer was end-labeled with ${ }^{33} \mathrm{P}$. Selective amplification products were electrophoresed using 6.0\% polyacrylamide gels for $2 \mathrm{~h}$ at $60 \mathrm{~W}$. After drying, gels were exposed to $\mathrm{x}$-ray film for 24 to $48 \mathrm{~h}$. To ensure repeatability of banding patterns, duplicate reactions were performed for isolates ANM, BAM, MSD, and SNC. Band sizes were estimated using a 30- to 330-bp AFLP DNA Ladder (Invitrogen).

Polymorphic fragments were scored visually from x-ray films as present (" 1 ") or absent ("0"). Faint or otherwise ambiguous fragments were conservatively scored as missing ("9"). Polymorphic information content for each individual marker $\left(\mathrm{PIC}_{\mathrm{i}}\right)$ was calculated according to the equation $\mathrm{PIC}_{\mathrm{i}}=1-\left[f^{2}+\right.$ $\left.(1-f)^{2}\right]$ where " $f$ " is the frequency of bands present and " $1-f$ " is the frequency of bands absent for the marker (De Riek et al., 2001). By this equation, $\mathrm{PIC}_{\mathrm{i}}$ values can range from 0 to 0.5 with greater values indicating increased ability of the markers to differentiate between isolates. The mean polymorphic information content for each primer pair $\left(\mathrm{PIC}_{\mathrm{m}}\right)$ was calculated by taking the average of $\mathrm{PIC}_{\mathrm{i}}$ for all polymorphic markers generated from the primer pair. The marker index for each primer pair is the sum of all $\mathrm{PIC}_{\mathrm{i}}$ for markers generated from that primer pair.

Table 2. Amplified fragment length polymorphism primer pairs evaluated and diagnostic marker data for four primer pairs used to amplify genomic DNA from 50 Diplocarpon rosae isolates.

\begin{tabular}{|c|c|c|c|c|c|}
\hline Primer pair & $\begin{array}{c}\text { Total } \\
\text { fragments } \\
\text { (no.) }\end{array}$ & $\begin{array}{l}\text { Polymorphic } \\
\text { Fragments } \\
\text { (no.) }\end{array}$ & $\begin{array}{c}\text { Polymorphic } \\
\text { fragments } \\
(\%)\end{array}$ & $\mathrm{PIC}_{\mathrm{m}}{ }^{\mathrm{z}}$ & $\mathrm{MI}^{\mathrm{y}}$ \\
\hline E-A, M-CT & 105 & 24 & 23 & 0.20 & 4.74 \\
\hline E-A, M-CA & 116 & 26 & 22 & 0.29 & 7.61 \\
\hline $\mathrm{E}-\mathrm{A}, \mathrm{M}-\mathrm{CC}$ & 84 & 17 & 20 & 0.27 & 4.52 \\
\hline E-A, M-CG & 62 & 11 & 18 & 0.26 & 2.87 \\
\hline E-ACC, M-CT & $38^{x}$ & & & & \\
\hline E-AC, M-CTC & $44^{x}$ & & & & \\
\hline $\mathrm{E}-\mathrm{AC}, \mathrm{M}-\mathrm{CT}$ & $47^{x}$ & & & & \\
\hline E-A, M-CT & $99^{x}$ & & & & \\
\hline E-A, M-CA & $109^{x}$ & & & & \\
\hline E-A, M-CC & $80^{\mathrm{x}}$ & & & & \\
\hline E-A, M-CG & $57^{x}$ & & & & \\
\hline
\end{tabular}

${ }^{\mathrm{z}}$ Mean polymorphic information content.

${ }^{\mathrm{y}}$ Marker index.

${ }^{\mathrm{x}}$ For isolates ANM, BAM, MSD, and SNC only; for determination of optimum primer length for selective amplification. 
Statistical AnAlysis. Marker data were analyzed using both phenetic and cladistic methodology. Jaccard and Dice similarity matrices were calculated from the marker data using the SIMQUAL module of NTSYSpc-2.20d software (Rohlf, 2000), and dendrograms were created using the unweighted pair-group method with arithmetic average (UPGMA) for both similarity matrices with the SAHN module. Goodness of fit for each similarity matrix was tested by cophenetic correlation using the COPH and MXCOMP modules. Bootstrap analysis was performed in the RESAMPLE and CONSENS modules with 100 replications. Principal component analysis was performed by calculating eigen vectors from the Jaccard similarity matrix in the EIGEN module of NTSYSpc-2.20d and constructing a biplot of principal component 1 versus principal component 2 . Cladistic analyses were also performed using the Dollo and Wagner methods in the DOLLOP and PARS modules, respectively, of PHYLIP 3.65 software (Felsenstein, 2004).

Analysis of molecular variance (AMOVA) was used to test the significance of geographic origin and host of origin. Data were prepared for AMOVA using the Transformer-2 macro (Caujapé-Castells and Baccarani-Rosas, 2004) in Excel (Microsoft, Redmond, WA), and AMOVA was performed with Arlequin 2.0 software (Schneider et al., 2000). For further examination of the effects of geographic origin on marker patterns, straight-line distances in miles between collection locations (Mapcrow, 2005) were used to construct a geographic distance matrix, which was then correlated to the Jaccard similarity matrix using the MXCOMP module of NTSYSpc2.20d (Rohlf, 2000).

\section{Results}

Initial AFLP reactions with E-ACC/M-CT, E-AC/M-CTC, and $\mathrm{E}-\mathrm{AC} / \mathrm{M}-\mathrm{CT}$ primer pairs yielded 38, 44, and 57 total bands, respectively, from isolates ANM, BAM, MSD, and SNC (Table 2). The number of selective nucleotides was reduced to $\mathrm{E}+1 / \mathrm{M}+2$ to obtain optimal band numbers. For the same four isolates, the primer pairs E-A/M-CT, E-A/M-CA, E-A/M-CC, and E-A/M-CG yielded an average of 86 total bands (Table 2). Final selective amplifications with primers E-A/M-CT, E-A/M$\mathrm{CA}, \mathrm{E}-\mathrm{A} / \mathrm{M}-\mathrm{CC}$, and $\mathrm{E}-\mathrm{A} / \mathrm{M}-\mathrm{CG}$ for all 50 isolates yielded 367 total fragments, of which $78(21 \%)$ were polymorphic (Table 2; Fig. 2). Averages of 91.8 total bands and 19.5 polymorphic bands were obtained per primer pair. For polymorphic bands, frequencies of bands present ranged from $2 \%$ (one of 50 isolates) to $98 \%$ (49 of 50 isolates). $\mathrm{PIC}_{\mathrm{m}}$ values for the primer pairs ranged from 0.20 to 0.29 , indicating that they were useful in discriminating between isolates. Colonies displayed considerable color diversity after $28 \mathrm{~d}$ of growth on PDA with colors ranging from dark black to beige, peach, and dark olive (not shown).

Geographic origin. Cophenetic correlations were greater for the Jaccard similarity matrix $(r=0.83)$ than for the Dice similarity matrix $(r=0.80)$; therefore, a UPGMA dendrogram was created from the Jaccard matrix (Fig. 3). Few strongly supported groupings were identifiable by cluster analysis as shown by few bootstrap values larger than 50. Most strikingly, isolates $\mathrm{HECH}$ and DDCH collected in Jemison, AL, had identical banding patterns as did isolates IGI and GMI collected in Ames, IA. Isolates CMI and LPI, also collected in Ames, group together (bootstrap value $=100$ ) but do not group closely with IGI and GMI. Other pairs such as isolates GVH and JCH (Hastings, MN) and isolates HEM and DDM (St. Louis, MO) follow the same pattern in that they group closely with one another (bootstrap values $=98$ ) but do not cluster with other isolates collected from the same locations. Beyond these few examples, well-supported clustering based on geographic origin is lacking. Similarly, there are no strong associations among isolates from distinct but geographically close locations. For example, isolates from Chanhassen, MN, and Hastings, $\mathrm{MN}$, do not cluster tightly together, although these locations are only $54.7 \mathrm{~km}$ apart.

The observation of poor geographic clustering is consistent with the extremely low $(\mathrm{r}=0.003)$ and nonsignificant $(P=0.48)$ correlation between the genetic similarity matrix (Jaccard) and the geographic distance matrix. AMOVA analysis of geographic location partitioned $100 \%$ of marker variability to the within-location source of variation and $0 \%$ of variability to the among-location source of variation. Principal component analysis yielded similar results (Fig. 4) with no strong geographic groupings present in a biplot of principal components 1 and 2 . Dendrograms constructed using the Dollo and Wagner cladistic parsimony methods revealed no significant clustering beyond that shown in the UPGMA cluster analysis (data not shown).

Host OF ORIGIN AND RACE. AMOVA analysis attributed 8.7\% of marker variation of $D$. rosae genotypes to the factor of host of origin. Only one race was represented by multiple isolates, so AMOVA was not performed with race as a factor. No genetic associations were observed in the clustering or principal

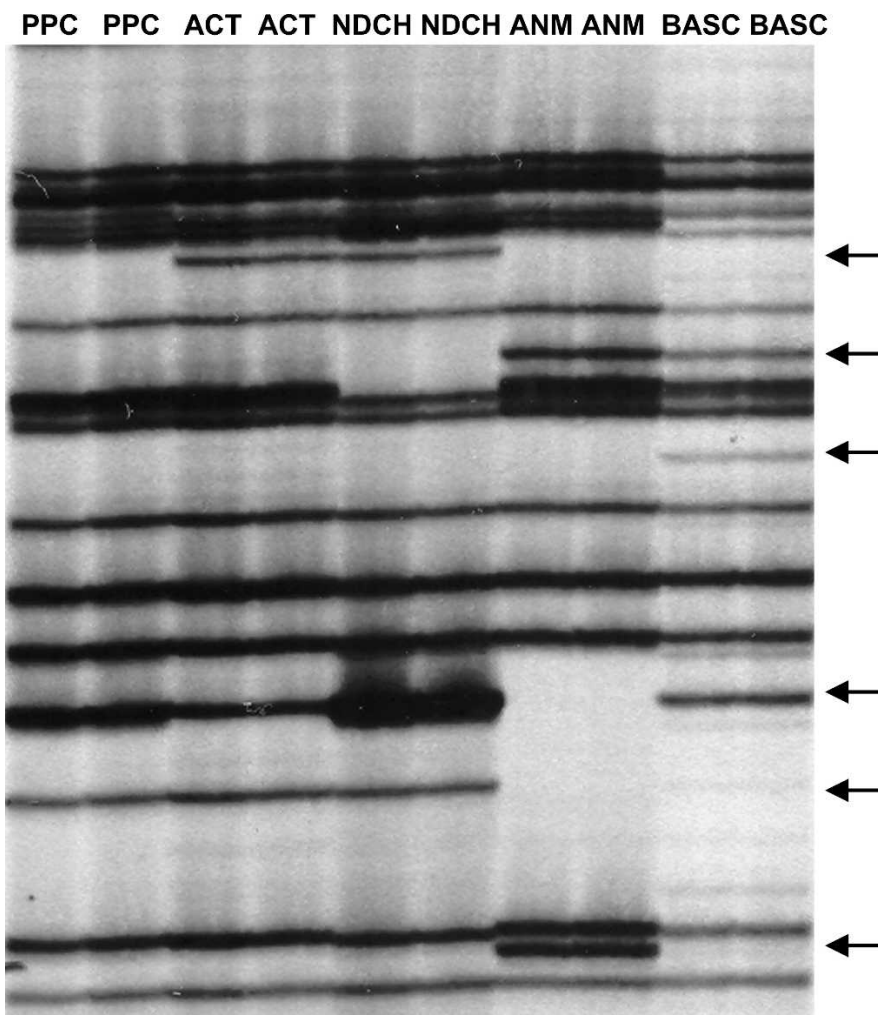

Fig. 2. Representative amplified fragment length polymorphism banding patterns of five different Diplocarpon rosae isolates. Pairs of lanes for each isolate represent duplicate selective amplifications from the same preamplified DNA using the primer pair E-A/M-CA. Isolates are described in Table 1. Arrows indicate polymorphic fragments. 


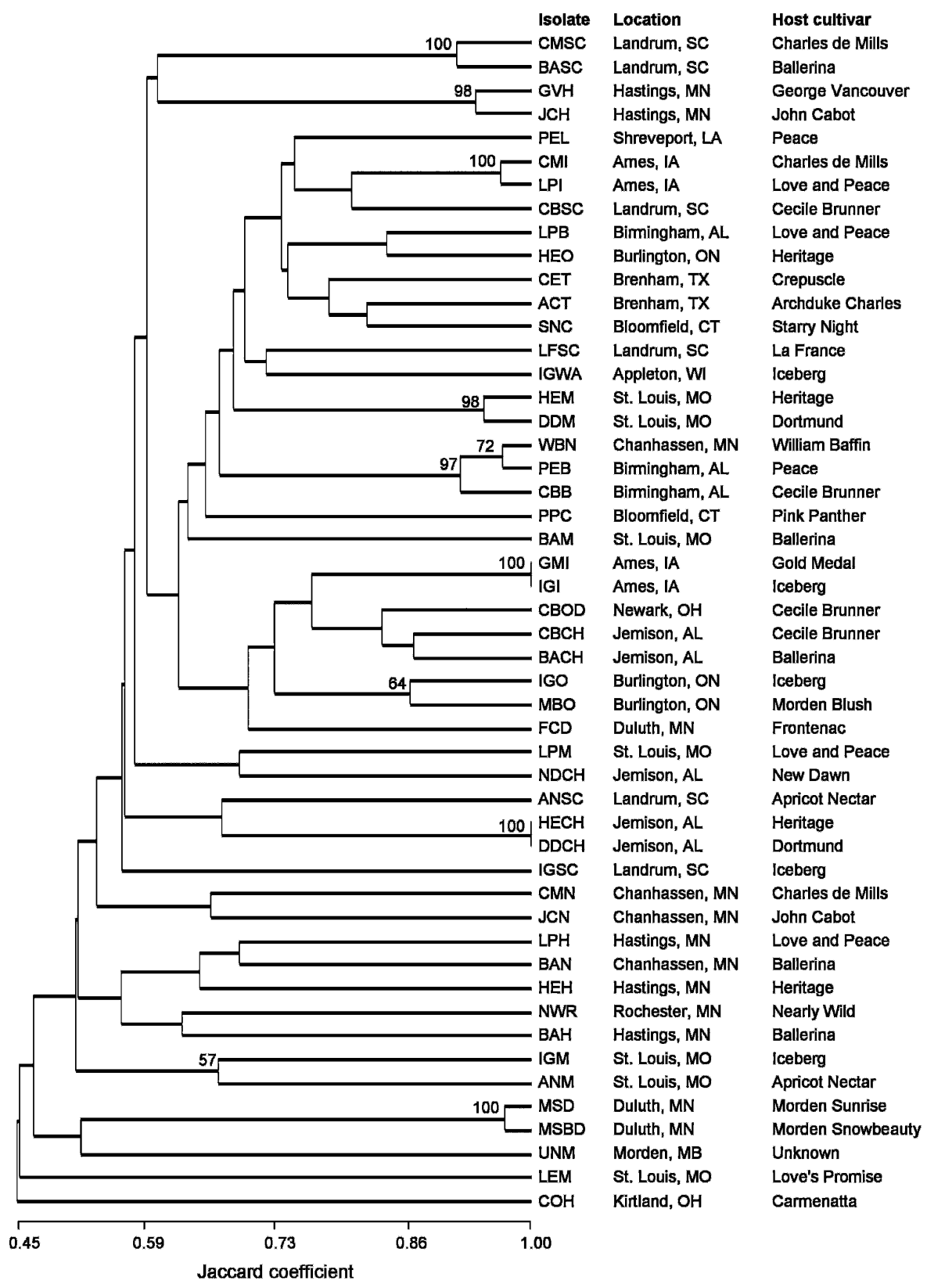

Fig. 3. Unweighted pair-group method with arithmetic average dendrogram constructed using Jaccard's coefficient of similarity from 78 amplified fragment length polymorphism markers generated from 50 singleconidial isolates of Diplocarpon rosae. Bootstrap percentages greater than 50 are indicated at branch nodes. The scale indicates Jaccard's coefficients.

component analyses based on either host of origin or race (Figs. 3 and 4$)$.

\section{Discussion}

The genetic diversity among isolates of phytopathogenic fungi, as measured by AFLP, has varied dramatically. Urbanitez and Dunemann (2005) analyzed a collection of 31 Podosphaera leucotricha Salm. (apple powdery mildew) isolates collected across Europe. Forty-three E $+3 / \mathrm{M}+3$ primer pairs yielded only $4.5 \%$ polymorphic bands $(1.3$ per primer pair) despite observed phenotypic and pathogenic diversity. In contrast, a study of 55 Kenyan isolates of Fusarium udum Butler (pigeon pea fusarium wilt) yielded an average of $37 \%$
Race polymorphic bands generated from seven different $\mathrm{E}+2 / \mathrm{M}+3$ primer

c pairs (Kiprop et al., 2002). The AFLP marker diversity among $D$.

A rosae isolates is intermediate to the two previous examples and comparable to that of more closely related phytopathogenic fungi from the Dermateaceae family. AFLP analysis of four isolates of Pyrenopeziza

A brassicae (Sutton and Rawl), a pathogen of Brassica L., collected across

B the United Kingdom yielded an A average of 60 total bands $(12.9 \%$ polymorphic) from 21 different $\mathrm{E}+2 /$

A $\mathrm{M}+2$ primers (Majer et al., 1996). Douhan et al. (2002) used $12 \mathrm{E}+2 /$ $\mathrm{T}+2$ (Tru9I is an isoschizomer of MseI) primers to study isolates of Tapesia yallundae Wallwork and

A Spooner collected from wheat plants (Triticum aestivum L.) in eastern Washington. They obtained an aver-

A age of 13.7 polymorphic bands per primer pair.

Optimum band numbers for final

A selective amplifications were achieved using shorter primers (E+1/

A $\mathrm{M}+2)$ than for the Dermateaceous fungi previously mentioned. Majer A et al. (1996) suggested that +1 primers may be required for fungal genomes smaller than $P$. brassicae. The $\mathrm{E}+1 / \mathrm{M}+2$ primer pair $\mathrm{E}-\mathrm{C} /$ M-AC was used for AFLP amplifications in a diversity study of yeasts, including Saccharomyces cerevisiae Meyen (Lopes et al., 1999), which

A has an estimated genome size of $\approx 12.2 \mathrm{Mb}$ (Broad Institute, Massachusetts Institute of Technology, 2005). However, it must be noted that the number of bands amplified can differ widely between primer pairs of the same length. In this study of $50 \mathrm{D}$. rosae isolates, total band numbers for $\mathrm{E}+1 / \mathrm{M}+2$ primers ranged from 62 to 116 . In the previously cited study of $F$. udum (Kiprop et al., 2002), seven $\mathrm{E}+2 / \mathrm{M}+3$ primers were used to amplify an average of 46.6 bands per primer pair with a range from 28 to 72 total bands. This demonstrates that comparisons of AFLP primer lengths and band numbers for a limited number of primer pairs should not be considered as accurate predictors of genome size. Therefore, the suitability of $\mathrm{E}+1 / \mathrm{M}+2$ primers for $D$. rosae suggests the possibility of a relatively small genome but does not constitute strong evidence.

The sexual stage of $D$. rosae has been reported only twice in North America and twice in England (Horst, 1983). Yet the genotypic and phenotypic diversity among North American isolates of $D$. rosae may be indicative of more sexual recombination in this fungus than has been reported. Similarly, 


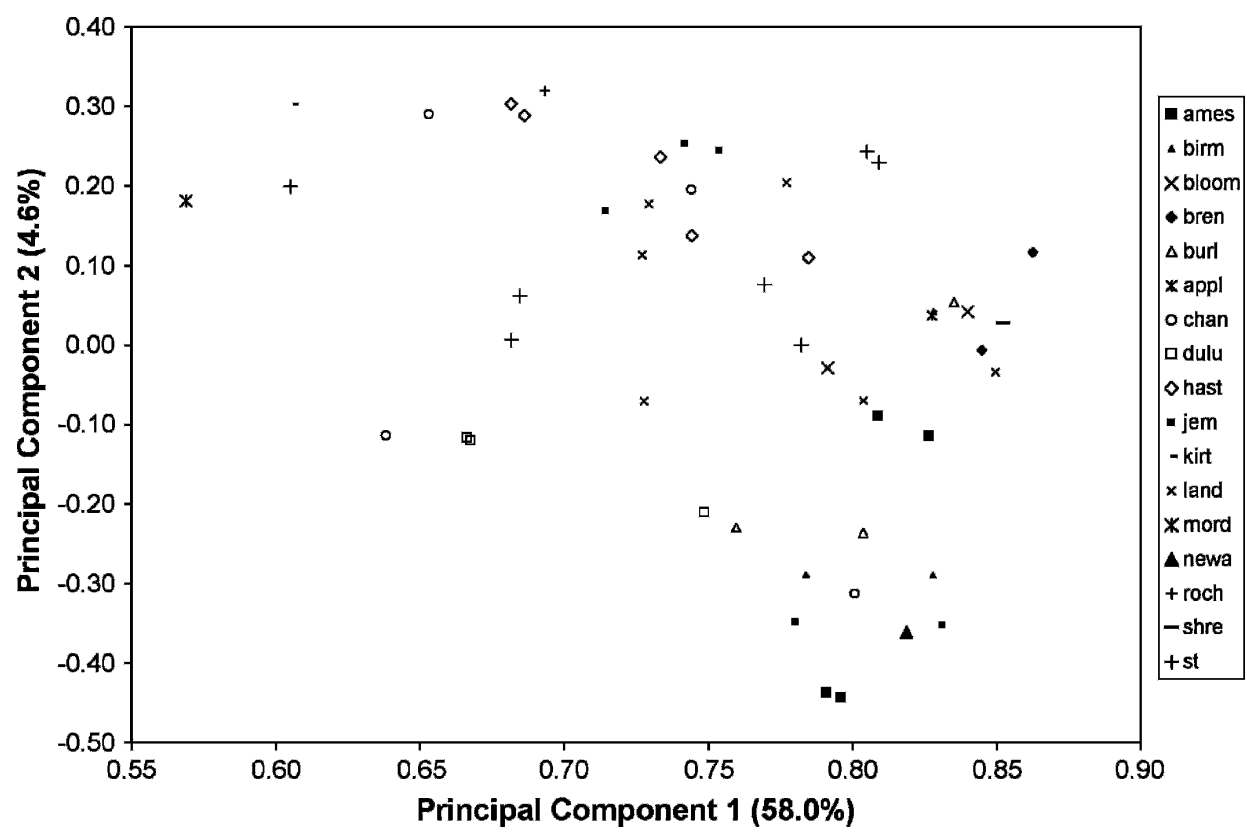

Fig. 4. Plot of the first two principal components from a principal component analysis of Jaccard's coefficient of similarity using 78 amplified fragment length polymorphism markers. Data points represent 50 single-conidial isolates of Diplocarpon rosae, each labeled according to geographic origin.

the sexual stage of $T$. yallundae had not been reported in the United States, yet high genetic diversity and segregation of specific markers demonstrated a history of sexual recombination in the populations under study (Douhan et al., 2002). Although sexual reproduction has been observed infrequently or not at all in many members of the Ascomycota, recent genetic studies have revealed recombination in several apparently asexual species (Taylor et al., 1999).

The Jaccard similarity matrix was chosen for the UPGMA dendrogram construction because of its greater cophenetic correlation as compared with Dice. Koopman et al. (2001) used cophenetic correlation to document the suitability of Jaccard over Dice for an AFLP analysis of Lactuca L. and speculated that Jaccard may be the most suitable for AFLP in general.

Identical banding patterns between isolates $\mathrm{HECH}$ and DDCH (Jemison, AL) and between isolates IGI and GMI (Ames, IA) strongly suggest that these isolates are, in fact, the same clone. Diplocarpon rosae propagates mainly through the production of abundant asexual conidia that are transported by free water. Therefore, short-distance dispersal by asexual conidia within a collection location is consistent with the occurrence of clones on different host plants within that location.

Several factors may contribute to poor association between geography and AFLP diversity in the collection as a whole. First, the movement of $D$. rosae in commerce between locations is likely to occur frequently, because roses are vegetatively propagated from stem cuttings or grafted onto rootstocks that may harbor spores or lesions. Our collection locations consisted of gardens with multiple rose cultivars that may have been transported long distances before establishment. Carlson-Nilsson (2002) described distinct clusters of D. rosae isolates from Sweden and from Manitoba, which could reflect a reduction in intercontinental versus intracontinental movement of vegetative rose propagules harboring $D$. rosae. Rose production in the
United States is concentrated in relatively few growing regions, which may have a homogenizing effect on the nationwide distribution of D. rosae diversity. California and Arizona account for most of the production area, with 20 to 22 million roses produced in those states yearly (D. Booty, personal communication). However, although black spot disease occurs in these growers' fields, disease incidence is lower in the southwestern United States because of decreased rainfall and humidity. Factors other than transport of diseased plant materials that may account for the observed lack of significant clustering include sexual recombination and accumulation of mutations.

Three races were discovered among 14 isolates randomly selected from the 50 isolates investigated in the present study with race $A$ being by far the most prevalent (Table 1; Fig. 3) (Whitaker et al., 2007b). Similar tests have differentiated multiple races within groups of $D$. rosae isolates collected from much smaller geographic areas (Debener et al., 1998; Spencer and Wood, 1992a, 1992b; Svejda and Bolton, 1980; Yokoya et al., 2000). Blechert and Debener (2005) microscopically observed multiple compatible and incompatible reaction types that differed between rose species inoculated with a single-conidial isolate. These findings indicate a high level of host specificity in the rose black spot pathosystem. However, no clustering according to host of origin was found in the present study. This is not surprising if we assume the "gene-for-gene" model in this pathosystem (Von Malek and Debener, 1998), in which host range limitations in rose are dictated by interactions of a small number of pathogenic avirulence genes with host resistance genes. Therefore, it is not expected that diversity at marker loci spanning the entire genome would correlate with host associations based on a few avirulence genes. The same avirulence genes may be present in a wide range of genetic backgrounds. Indeed, race $\mathrm{A}$ in this study is represented by 12 isolates that are quite genetically diverse (Fig. 3).

In summary, our collection of 50 single-conidial isolates of $D$. rosae from eastern North America contains significant genetic diversity based on AFLP analysis and phenotypic diversity based on colony color and pathogenicity. Phenetic and cladistic analyses reveal minimal clustering of isolates based on geographic origin and host of origin, although the data are consistent with short-range dispersal within locations by asexual conidia. We have documented that a single race can be represented by several genetically diverse isolates, which may be reflected in poor clustering based on host of origin. Lack of significant groupings based on geographic origin is likely the result of the movement of $D$. rosae on rose propagules in commerce. This absence of clustering also raises the question of whether diversity within collection locations could be reflective of sexual recombination, which would require a more extensive study. A larger survey including more isolates from 
each collection location could also reveal subtle differences among populations that were not detected here.

As a result of the lack of geographic structuring of $D$. rosae diversity, rose breeders with target markets in eastern North America might be justified in conducting black spot host resistance screening in only one geographic region. Caution must be exercised, however, because the relationship between AFLP marker diversity and pathogenicity is still unclear. In addition, significant diversity of $D$. rosae within small areas may lead to inaccuracies in field screening, because several pathogenic variants may be unevenly distributed within the same plot. Ideally, the establishment of a comprehensive $D$. rosae race collection and continual monitoring for new races will allow for more accurate screening through artificial inoculations with single-spore isolates under controlled conditions. We are currently using controlled inoculations of these races to genetically analyze race-specific resistance in germplasm from the University of Minnesota rose breeding program. Furthermore, an understanding of the worldwide distribution of $D$. rosae diversity would be of great value to the breeding effort and should be obtained in future studies.

\section{Literature Cited}

Blechert, O. and T. Debener. 2005. Morphological characterization of the interaction between Diplocarpon rosae and various rose species. Plant Pathol. 54:82-90.

Broad Institute, Massachusetts Institute of Technology. 2005. Status of FGI projects. Fungal genome initiative. 1 Oct. 2005. <www. broad.mit.edu/annotation/fgi/status.html>

Carlson-Nilsson, U.B. 2002. Variation in Rosa with emphasis on the improvement of winter hardiness and resistance to Marssonina rosae (blackspot). Swedish University of Agricultural Sciences, Alnarp, PhD Diss.

Caujapé-Castells, J. and M. Baccarani-Rosas. 2004. Transformer-2: A program for the analysis of molecular population genetic data. Jardín Botánico Canario 'Viera y Clavijo' and Instituto Tecnológico de Canarias, Las Palmas de Gran Canaria, Spain.

De Riek, J., E. Calsyn, I. Everaert, and E. Van Bockstaele. 2001. AFLP based alternatives for the assessment of distinctness, uniformity and stability of sugar beet varieties. Theor. Appl. Genet. 103:1254-1265. Debener, T., R. Drewes-Alvarez, and K. Rockstroh. 1998. Identification of five physiological races of blackspot, Diplocarpon rosae Wolf, on roses. Plant Breed. 117:267-270.

Dobbs, R.B. 1984. Research battles blackspot in roses. Amer. Rose Annu. 69:44-54.

Douhan, G.W., T.L. Peever, and D. Murray. 2002. Multilocus population structure of Tapesia yallundae in Washington state. Mol. Ecol. 11:2229-2239.

Drewes-Alvarez, R. 2003. Disease: Black spot, p. 148-153. In: Roberts, A.V., T. Debener, and S. Gudin (eds.). Encyclopedia of rose science. Elsevier Academic Press, Oxford, UK.

Felsenstein, J. 2004. Phylogeny inference package ver. 3.65. Department of Genome Sciences and Department of Biology, University of Washington, Seattle.

Horst, R.K. 1983. Compendium of rose diseases. APS Press, St. Paul, MN.
Kiprop, E.K., J.P. Baudoin, A.W. Mwang'ombe, P.M. Kimani, G. Mergeai, and A. Maquet. 2002. Characterization of Kenyan isolates of Fusarium udum from pigeonpea [Cajanus cajan (L.) Millsp.] by cultural characteristics, aggressiveness and AFLP analysis. J. Phytopathol. 150:517-525.

Koopman, W.J.M., M.J. Zevenbergen, and R.G. Van den Berg. 2001. Species relationships in Lactuca s.1. (Lactuceae, Asteraceae) inferred from AFLP fingerprints. Amer. J. Bot. 88:1881-1887.

Lee, H.T., H.D. Shin, S.B. Hong, and S.J. Go. 2000. rDNA RFLP analysis of Marssonina coronaria and M. rosae. Mycobiology 28:211 (Abstr.).

Lopes, M., S. Rainieri, P.A. Henschke, and P. Langridge. 1999. AFLP fingerprinting for analysis of yeast genetic variation. Int. J. Syst. Bacteriol. 49:915-924.

Majer, D., R. Mithen, B.G. Lewis, P. Vos, and R.P. Oliver. 1996. The use of AFLP fingerprinting for the detection of genetic variation in fungi. Mycol. Res. 100:1107-1111.

Mapcrow. 2005. Travel distance calculator between cities. 1 Oct. 2005. <www.mapcrow.info>.

Rohlf, F.J. 2000. NTSYS-Pc: Numerical taxonomy and multivariate analysis system. Exeter Publishers, Setauket, NY.

Schneider, S., D. Roessli, and L. Excoffier. 2000. Arlequin ver. 2.000: A software for population genetics data analysis. Genetics and Biometry Laboratory, University of Geneva, Switzerland.

Spencer, J.A. and O.W. Wood. 1992a. Response of selected old garden roses to seven isolates of Marssonina rosae in Mississippi. J. Environ. Hort. 10:221-223.

Spencer, J.A. and O.W. Wood. 1992b. Resistance of selected rose cultivars to variants of Marssonina rosae in Mississippi. J. Environ. Hort. 10:235-238.

Svejda, F.J. and A.T. Bolton. 1980. Resistance of rose hybrids to three races of Diplocarpon rosae. Can. J. Plant Pathol. 2:23-25.

Taylor, J.W., D.J. Jacobson, and M.C. Fisher. 1999. The evolution of asexual fungi: Reproduction, speciation and classification. Annu. Rev. Phytopathol. 37:197-246.

Urbanitez, A. and F. Dunemann. 2005. Isolation, identification and molecular characterization of physiological races of apple powdery mildew (Podosphaera leucotricha). Plant Pathol. 54:125-133.

Von Malek, B. and T. Debener. 1998. Genetic analysis of resistance to blackspot (Diplocarpon rosae) in tetraploid roses. Theor. Appl. Genet. 96:228-231.

Vos, P., R. Hogers, M. Bleeker, M. Reijans, T. van de Lee, M. Hornes, A. Frijters, J. Pot, J. Peleman, M. Kuiper, and M. Zabeau. 1995. AFLP: A new technique for DNA fingerprinting. Nucleic Acids Res. 23:4407-4414.

Wenefrida, I. and J.A. Spencer. 1993. Marssonina rosae variants in Mississippi and their virulence on selected rose cultivars. Plant Dis. 77:246-248.

Whitaker, V.M., K. Zuzek, J. Bradeen, and S.C. Hokanson. 2007a. Culturing and long-term storage of virulent races of the rose blackspot pathogen, Diplocarpon rosae Wolf. Acta Hort. 126:83-88.

Whitaker, V.M., K. Zuzek, and S.C. Hokanson. 2007b. Resistance of twelve rose genotypes to fourteen isolates of Diplocarpon rosae (rose blackspot) collected from eastern North America. Plant Breed. 126:83-88.

Yokoya, K., K.I. Kandasamy, S. Walker, Z. Mandegaran, and A.V. Roberts. 2000. Resistance of roses to pathotypes of Diplocarpon rosae. Ann. Appl. Biol. 136:15-20. 